\title{
Diagnostic value of nucleolar organizer regions (AgNORs) in brush biopsies of suspicious lesions of the oral cavity
}

\author{
Torsten W. Remmerbach ${ }^{\mathrm{a}, *}$, Horst Weidenbach ${ }^{\mathrm{b}}$, Conrad Müller ${ }^{\mathrm{a}}$, Alexander Hemprich ${ }^{\mathrm{a}}$, \\ Natalja Pomjanski ${ }^{\mathrm{c}}$, Birgit Buckstegge ${ }^{\mathrm{c}}$ and Alfred Böcking ${ }^{\mathrm{c}}$ \\ ${ }^{a}$ Department of Oral, Maxillofacial and Facial Plastic Surgery, University of Leipzig, Nürnberger Straße 57, \\ D-04103 Leipzig, Germany \\ ${ }^{\mathrm{b}}$ Institute of Pathology, University of Leipzig, Liebigstraße 26, D-04103 Leipzig, Germany \\ c Institute of Cytopathology, Heinrich Heine University, Moorenstraße 5, D-40225 Düsseldorf, Germany
}

\begin{abstract}
Objective: The aim of this retrospective study was to report on the diagnostic accuracy of AgNOR-analysis as an adjunctive diagnostic tool of conventional oral exfoliative cytology taken from suspicious lesions in our clinic. Study design: Cytological diagnoses obtained from brush biopsies of macroscopically suspicious lesions of the oral mucosa from 75 patients (final diagnoses: 53 histologically proven squamous cell carcinomas, 11 leukoplakias and other inflammatory oral lesions) and from 11 patients with normal mucosa as a negative control group were compared with histological and/or clinical follow-ups. Five smears were doubtful and seven suspicious for tumor cells in the cytologic report. Number of AgNOR's were counted in 100 squamous epithelial cell-nuclei per slide after silver-restaining. Results: Sensitivity of our cytological diagnosis alone on oral smears for the detection of squamous carcinomas was $92.5 \%$, specificity $100 \%$, positive predictive value was $100 \%$ and negative $84.6 \%$. The best cut-off value of the mean number of AgNOR dots per nucleus distinguishing benign from malignant cells was 4.8. The percentage of nuclei with more than three AgNORs had a cut-off level of 70\%. Applying these methods to twelve doubtful or suspicious cytological diagnoses we were able to correctly establish the diagnosis of malignancy in ten cases of histologically proven cancers and to reveal benignity in two histologically proven cases. Thus we achieved a positive and negative predictive value of $100 \%$ each. Conclusions: Smears from brushings of visible oral lesions, if clinically considered as suspicious for cancer, are an easily practicable, non-invasive, painless, safe and accurate screening method for detection of oral cancerous lesions. We conclude that AgNOR-analysis may be a useful adjunct to other methods in routine cytological diagnosis of oral cancer that can help to solve cytologically suspicious or doubtful cases.

Colour figures can be viewed on http://www.esacp.org/acp/2003/25-3/remmerbach.htm.
\end{abstract}

Keywords: Oral cancer, brush biopsy, AgNOR-analysis, cancer screening, diagnostic accuracy

\section{Introduction}

Squamous cell carcinomas (SCCs) of the oral cavity are among the ten most common cancers in the world, accounting for approximately $3-5 \%$ of all malignancies [32]. In 1993 in Germany, approximately 4100 new cases in males and 1000 in females were encountered [27]. The prognosis for many of these patients is devastating. Approximately $50 \%$ of the patients will die in the first five years after diagnosing

*Corresponding author: Dr. Torsten W. Remmerbach. Tel.: +49 (0) 3419721100; Fax: +49 (0) 3419721109; E-mail: remmt@ medizin.uni-leipzig.de. cancer [14]. There is a need to promote early diagnosis of oral cancers in order to reduce the currently unacceptably high morbidity and mortality rate. Exfoliative cytology performed on oral brushings can help dentists and other physicians to decide, whether a given oral lesion is (pre-)malignant or not [23]. Thus we achieved a sensitivity of $94 \%$ detecting SCC and a specificity of $99.5 \%$. Applying adjuvant DNA-cytometry we were able to increase sensitivity up to $98 \%$ and specificity up to $100 \%$. But an image-cytometer is not available in all institutes and the equipment is rather expensive. Therefore our aim was to make the diagnostic procedure simpler and more inexpensive as far as the required equip- 
ment is concerned. Another aim was to further increase diagnostic sensitivity.

In the last few years, silver staining of nucleolar organizer regions-associated proteins (AgNORs) has become a frequently used method in tumor pathology mainly for assessing the prognosis of malignant tumors. NORs represent loops of DNA actively transcribing to ribosomal RNA and hence to ribosomes and ultimately to proteins $[10,12]$. NORs are associated with acidic, argyrophylic, non-histonic proteins that are visualized using a silver staining technique [13, 22]. The ribosomal genes bearing NORs are localised on the short arms of the acrocentric chromosomes 13 , 14, 15, 21 and 22 [15]. Each of these chromosomes carries two NORs: Therefore, the number of NORs in normal diploid cells is 20 , typically aggregated in nucleoli during nuclear interphase [5]. Most recent studies showed that the number and/or the size of the argyrophylic NORs (AgNORs) correlate positively with the ribosomal gene activity and therefore with cellular proliferation [8,9,19,21,31]. The AgNOR technique has been successfully applied in histopathology in a wide variety of neoplastic lesions in order to distinguish benign from malignant ones $[7,11,28]$, including histological sections of oral cancer.

In cytologic preparations, the AgNOR technique has also been used. However, some studies have demonstrated good results with ethanol-fixed smears, e.g., of fine needle aspiration biopsies from salivary lesions [3,22]. Quantification of AgNORs in nucleoli in cyto- logical specimens has the important advantage relating results to whole individual nuclei avoiding problems arising from the evaluation of nuclear fragments [30].

In this study we investigated if counting AgNORs per 100 nuclei of exfoliated cells can contribute to an objective diagnosis of oral squamous cell carcinoma in brush biopsies.

\section{Materials and methods}

\subsection{Patient population}

The study population consisted of 337 smears obtained from 75 patients ( $25.3 \%$ females, $74.7 \%$ males) with a mean age of 55.9 years (range 22-91 years), who had been referred for examination and treatment of oral lesions to the Department of Oral Maxillofacial and Facial Plastic Surgery, University of Leipzig, Germany between August 1997 and October 2001. The brush biopsies were obtained and diagnosed before scalpel biopsies clarified the dignity of the oral lesion histologically. The quantification of AgNORs was performed blinded without knowledge of the histological rsp. cytological report. The "gold standard" for the establishment of diagnostic accuracy was the (repeated) histological diagnosis in 64 cases and clinical follow up in all cases. Final diagnoses were: 53 histologically proven squamous cell carcinomas (Table 1), 22 leukoplakias (according to World Health Organisation de-

Table 1

Synopsis about tumor site and tumor spread of 53 patients with squamous cell carcinoma of the oral cavity

\begin{tabular}{lcc}
\hline & $\begin{array}{c}\text { Number of cases }(n=53) \\
\text { clinical staging }\end{array}$ & $\begin{array}{c}\text { Number of cases }(n=53) \\
\text { pathological staging }\end{array}$ \\
\hline Tumor sites & 6 & 6 \\
floor of the mouth & 12 & 12 \\
floor of the mouth and tongue & 11 & 11 \\
tongue & 0 & 0 \\
lip & 10 & 10 \\
tonsil and palate & 7 & 7 \\
alveolar ridge & 7 & 7 \\
cheek & & \\
Tumor spread & 4 & 3 \\
Tis & 14 & 14 \\
T1 & 12 & 12 \\
T2 & 10 & 11 \\
T3 & 12 & 10 \\
T4 & 1 & 3 \\
Tx & &
\end{tabular}


Table 2

Synopsis about clinical or histological diagnoses and number of smears of all oral lesions $(n=75)$

\begin{tabular}{lcccc}
\hline & Total & $\begin{array}{c}\text { Histologically } \\
\text { proven }\end{array}$ & $\begin{array}{c}\text { Clinical } \\
\text { follow-up }\end{array}$ & $\begin{array}{c}\text { Number of } \\
\text { smears }\end{array}$ \\
\hline Leukoplakia & 5 & 5 & - & 25 \\
Lichen planus & 2 & 2 & - & 10 \\
Lichen erosivus & 3 & 3 & - & 15 \\
Ulcus & 1 & - & 1 & 4 \\
Negative control & 11 & - & 11 & 50 \\
Squamous cell & 53 & - & 53 & 165 \\
$\quad$ carcinoma & & & & \\
\hline
\end{tabular}

finition [33]) or other inflammatory oral lesions. 11 smears from inconspicuous buccal mucosa were obtained from unsolicited students (clinical follow-up after 4 weeks) as shown in Table 2.

\subsection{Clinical procedure}

Each patient was examined by an experienced member (T.W.R.) of the Department of Oral-, Maxillofacial and Facial Plastic Surgery. Before the cytologic brushings were performed, each patient's medical history was documented and a thorough extra- and intraoral examination was performed. After these evaluations, at least four cytological smears were obtained from the suspicious or pathological mucosal areas using a cytobrush cell collector (Cytobrush GT, Med-Scand Medical, Malmo, Sweden) [20]. The cytobrush was rolled on the glass slide at five different sites and fixed immediately using Merckofix-spray (Merck, Darmstadt, Germany), a propanol and carbowax containing fixative.

\subsection{Staining and mode of interpretation}

The alcohol fixed slides were routinely stained according to Papanicolaou (PAP) [17]. The specimens were evaluated by an experienced cytotechnologist in compliance to generally accepted diagnostic criteria $[1,17]$ as well as by an experienced cytopathologist (A.B.) in cytologically doubtful, suspicious or tumor cell positive slides. Cytological diagnoses were assigned to the following diagnostic categories of cytological diagnoses: "insufficient" for specimens without any or with exclusively autolytic cells, "tumor cell negative" for inconspicuous, reactive or inflammatory cellular images, "doubtful" in cases with abnormal cellular changes (e.g., with mild or moderate dysplasias), "suspicious for tumor cells" if only sparce abnormal cells (or severe dysplastic squamous cells) were seen or if the diagnostic criteria for malignancy were only vague and "tumor cell positive" for smears containing unequivocal malignant cells [2].

\subsection{AgNOR-staining}

Silver staining was performed according to the one step method by Ploton et al. [22], Crocker et al. [6] and Rüschoff [24], with some modifications. Routine Papanicolaou-stained smears from brushings of suspicious oral lesions were uncovered in xylene. For AgNOR staining, the smears were placed in xylene for $5 \mathrm{~min}$, then fixed in absolute ethanol for $5 \mathrm{~min}$ and in a mixture of $100 \mathrm{ml} 96 \%$ ethanol with 5 drops acetic acid for an additional $5 \mathrm{~min}$ and then progressively rehydrated. The AgNOR-staining was carried out using a solution consisting of one volume of $2 \%$ gelatine in $1 \%$ aqueous formic acid and two volumes of $50 \%$ silver-nitrate. The incubation was performed at room temperature for 20 minutes in the dark. After staining, the slides were placed in a dark container, washed three times in deinoized distilled water and merged in $10 \%$ thiosulfate for $10 \mathrm{~min}$. The smears were then washed for $5 \mathrm{~min}$ in tap-water, dehydrated to xylene and mounted in a synthetic medium. The slides were then stored in darkness.

\section{Counting procedure}

AgNOR counting was performed on 100 randomly selected normal respective abnormal squamous cells for each cytologic smear. These were examined under a $1,000 \times$ magnification (Achroplan ${ }^{\mathrm{TM}} 100 \times / 1.25$ oil/0.17; W-PL $10 \times / 23$ ) in oil immersion. To standardise counting, we followed Crocker's method [6]. Firstly, all silver stained structures were counted, both lying in groups (clusters) and as individual dots [28] outside the clusters. Secondly, clusters and partly disaggregated dots were considered as one structure and were counted together with small ones lying separately. Thirdly, all AgNORs within clusters and the number of clusters were counted. Fourthly, just the number of individual dots (satellites) were counted. The mean number per nucleus of AgNORs as clusters, as satellites, as clusters and satellites together and all AgNORs lying together in clusters and as satellites were calculated in each case. The counting procedure took 45-90 minutes per smear. 


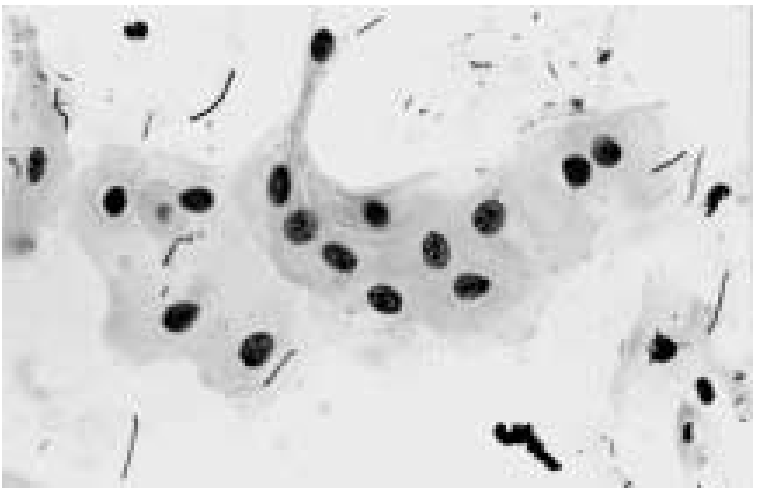

Fig. 1. Normal superficial squamous epithelial cells. Silver stained for AgNOR-analysis. Only few NORs are visible within nucleoli. $100 \times$ objective.

Additionally we evaluated the diagnostic potential of the percentage of nuclei with more than three, four and five AgNORs per cell (pAgNOR) according to Crocker et al. [9] and Rüschoff et al. [25]. Examples are shown in Figs 1 and 2.

\section{Results}

Colour figures can be viewed on http://www.esacp. org/acp/2003/25-3/remmerbach.htm.

\subsection{Cytological analysis}

Of technically sufficient brushings from suspicious oral lesions (Tables 1, 2) a non-malignant diagnosis (= tumor cell negative) was made cytologically in 23 cases. Five cases were doubtful for tumor cells. The medical reports showed, that in 53 specimens diagnosed as suspicious or tumor cell positive, squamous cell carcinomas were verified by subsequent histopathological diagnosis (correctly positive). In one case of histologically proven squamous cell carcinoma the smears were cytologically diagnosed as negative for tumor cells. Reevaluation of the respective smears showed obviously that no atypical or abnormal cells could be observed, thus a sampling error had occurred (false-negative). In 22 cases without carcinomas in the clinical follow up cytology reported: "negative for tumor cells" (correctly negative).

Sensitivity of our cytological diagnoses in oral smears for the detection of cancer cells was thus $92.5 \%$, specificity for the detection of non neoplastic cells $100 \%$, positive predictive value $100 \%$ and negative predictive value $84.6 \%$ (Table 3 ).

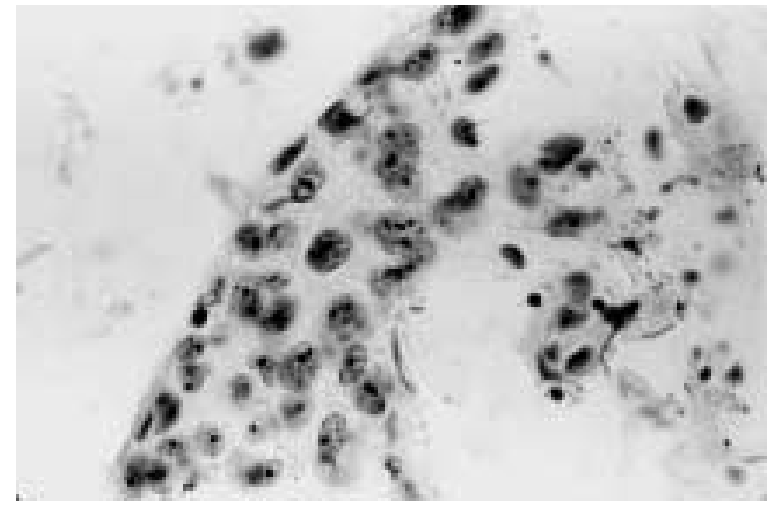

Fig. 2. Squamous carcinoma cells revealing multiple NORs as clusters (within nucleoli) and as satellites (outside nucleoli). $100 \times$ objective.

\section{Table 3}

Sensitivity and specificity of cytology versus histology in oral lesions $(n=75$ cases $)$

\begin{tabular}{clcc}
\hline \multicolumn{2}{c}{ Cytology } & \multicolumn{2}{c}{ Histology } \\
\cline { 3 - 4 } & & $\begin{array}{c}\text { Negative for } \\
\text { tumor cells }\end{array}$ & $\begin{array}{c}\text { Positive for } \\
\text { tumor cells }\end{array}$ \\
\hline Negative for & Negative & 20 & 1 \\
tumor cells & Doubtful & 2 & 3 \\
Positive for & Suspicious & 0 & 7 \\
tumor cells & Positive & 0 & 42 \\
\hline
\end{tabular}

\subsection{AgNOR analysis}

AgNORs were strictly located only within nuclei and were clearly visible as distinct black or dark-brown dots. Figure 3 present the distribution of the AgNOR counts in different cytologic categories.

Normal epithelial cells revealed one to two clusters (mean 0.03; SD 0.01) with one to six dots in each cluster (mean 2.28; SD 1.7). Some cells also contained satellites, even up to ten satellites were found lying outside the clusters. The silver reaction in neoplastic cells generally showed more dots as satellites and clusters. The number of dots lying within clusters was 2-6 for SCC (mean 2.28; SD 1.95).

The total AgNOR count, including the number of dots lying within clusters and as dots (satellites) are shown in Fig. 3. The mean number of all AgNOR dots per nucleus was 3.39 (SD 0.41 in inflammatory lesions, 3.88 (SD 0.59) in oral leukoplakias and 8.99 (SD 2.64) in OSCCs.

The distribution of mean AgNOR numbers per nucleus counting all lying in groups (clusters) and disaggregated dots as one structure together with those 


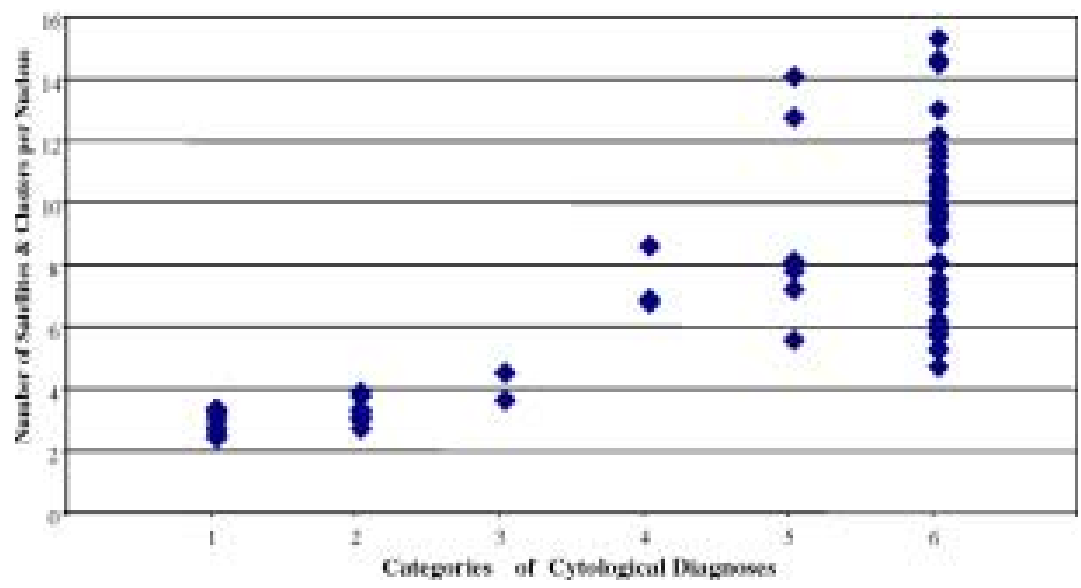

Fig. 3. Mean values of satellites $\&$ content of clusters. Categories of cytological diagnoses: $1=$ no tumor cells (negative control), $2=$ no tumor cells (benign mucosal lesion), $3=$ doubtful (histologically no sign of malignancy), $4=$ doubtful (histologically proven cancer), $5=$ suspicious (histologically proven cancer), $6=$ squamous cell carcinoma (histologically proven cancer). This figure can be viewed on http:// www.esacp.org/acp/2003/25-3/remmerbach.htm

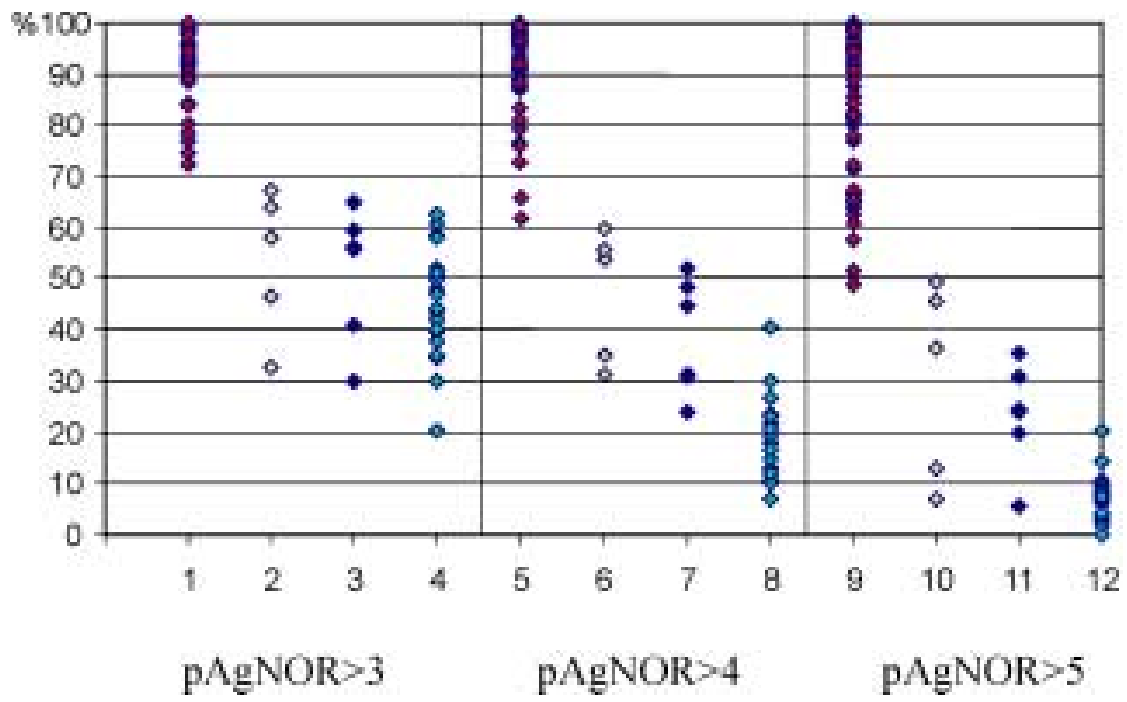

Fig. 4. Percentage of nuclei with AgNORs frequency distribution according to type of histologically proven mucosal lesions. $1,5,9=$ Oral squamous cell carcinomas; $2,6,10=$ oral leukoplakias; 3, 7, $11=$ inflammatory lesions; 4, 8, $12=$ normal epithelium; $1-4=$ percentage of nuclei with more than three AgNORs per cell; $5-8=$ percentage of nuclei with more than four AgNORs per cell; 9-12 = percentage of nuclei with more than five AgNORs per cell. This figure can be viewed on http://www.esacp.org/acp/2003/25-3/remmerbach.htm

lying separately is not shown (satellites). Briefly, the mean number of AgNOR dots per nucleus was 3.46 (SD 0.45) in inflammatory lesions, 3.79 (SD 0.62) in oral leukoplakias and 8.82 (SD 2.60) in OSCCs.

The mean number of AgNOR dots as satellites per nucleus was 3.35 (SD 0.35) in inflammatory lesions, 3.78 (SD 0.64) in oral leukoplakias and 8.67 (SD 2.55) in OSCCs (data not shown). The best cut-off value of the mean number of AgNORs per nucleus distinguishing benign from malignant cells was 4.8 .
The percentage of nuclei with more than three AgNORs per cell showed in comparison to the percentage of more than four or five AgNORs the clearest cut-off value using a $70 \%$ level (Fig. 4).

Sensitivity of our AgNOR-analysis in oral smears for the detection of oral cancer was $100 \%$, while specificity for the detection of non neoplastic cells also was $100 \%$. Application of this method to twelve doubtful or suspicious cytological diagnoses established the unequivocal diagnosis of malignancy in ten cases of 
Table 4

Sensitivity and specificity of AgNOR-analysis versus histology in oral lesions ( $n=75$ cases)

\begin{tabular}{ccc}
\hline AgNOR analysis & \multicolumn{2}{c}{ Histology } \\
\cline { 2 - 3 } & Negative & Positive \\
& for tumor cells & for tumor cells \\
\hline$<4.8$ & 22 & 0 \\
$>4.8$ & 0 & 53 \\
\hline
\end{tabular}

* Mean number of AgNOR dots per nucleus.

histologically proven cancer and revealed benignity in two histologically proven cases. Thus we achieved a positive and negative predictive value of $100 \%$ (Table 4). $32 \%$ of all patients with oral cancer diagnosed cytologically were identified in early stages T1N0 or as c.i.s.

We compared AgNOR counts of cells collected from normal buccal mucosa of cigarette smokers (quantum: max. 10 cig./day) with those obtained from non smokers in the negative control group. The mean AgNOR value for the smoking group was $2.4 \pm 0.54 \mathrm{AgNORs}$ and $2.6 \pm 0.49$ for the non smoking group; there was no significant difference between these groups. Likewise there was no significant difference between males or females.

\section{Discussion}

The assessment of AgNORs has been recognised in recent years making a useful contribution to routine histopathology. The method has also been applied successfully in cytologic smears. This technique has been used to differentiate between benign and malignant cells in several tissues, mainly using the mean number of AgNOR precipitations per nucleus. The method is applicable with simple light microscopes without additional and expensive technical options. High labor costs in the western hemisphere could restrict the application in routine diagnostic practice, because of its increased consume of time.

Many papers report about the diagnostic value of AgNOR counting dealing with formalin fixed, paraffin embedded specimens. They reported that after silver staining the NORs appear as black or deeply brown dots of various number and size within the nuclei, which reveal a yellow or yellowish-brown colour and sharp contours. This correlates with our observations. Xie et al. [34] report, that the percentage of nuclei with AgNORs $>2$, appeared to be a useful tool distinguishing between sections of normal epithelium, dysplasia and SCCs of the oral cavity. They refered no overlap between normal epithelium and SCCs. Yet, Zöller et al. [35] found no statistically significant relationship between the mean numbers of nucleoli and the mean AgNOR counts per nucleus to discriminate between biopsies of SCCs and normal oral tissues. This was true for tumors as well as for the dysplasias.

In the present study the AgNOR method was applied to oral brush biopsies in order to establish a diagnostic aid distinguishing malignant from benign cases. Cytological diagnosis of oral cancer cells is difficult and needs much experience. Its application is thus limited by the availability of highly specialised cytopathologists. The availability of a technically simple adjuvant method on smeared cells, which allows an objective and unequivocal identification of cancer cells in oral smears could greatly enhance the applicability of oral cytology as an accurate method for early diagnosis of cancer in the mouth.

Crocker et al. [6-9] describe two different methods of AgNOR counting: firstly, all silver stained structures, but when lying in groups each cluster (almost aggregated or partly disaggregated nucleoli) was counted as one structure; secondly, where AgNORs can be seen separately within a nucleus, each AgNOR could be counted as a unit, together with smaller ones seen outside the nucleolus. Shechtman et al. [28] counted large clusters of AgNORs and small, individual dots (satellites) separately. Most authors performed AgNOR-counting also at $1,000 \times$ magnification under oil immersion $[4,16,27,29]$. In some studies quantitative analysis was performed using image processing; in these areas AgNORs per nucleus were investigated.

Only two investigators dealt with cytologic materials (scrapings or brushings) of the oral cavity. One paper, which investigated the value of AgNOR counting on scrape cytology distinguishing between benign and malignant smears of the oral cavity in 26 cancer patients: Mao [18] reports mean AgNOR counts per nucleus in the cancer group of $4.69 \pm 0.72$ and $2.44 \pm 0.37$ for normal mucosa $(n=26)$. The statistical analysis of the AgNOR counts showed that the mean values for the cancerous lesions were significantly higher than those of normal mucosa $(p<0.005)$. He found no overlap between both groups. Our results are basically in agreement with the data of Mao. Yet, our mean value for the cancer group is much higher than his. This could be a result of the staining method used: the staining was performed for one hour and thus small sized dot-like precipitations merge and the discrimination between small individual dots may not to be possible. 
Sampaio et al. [26] compared AgNOR counts of cells collected from normal buccal mucosa of cigarette smokers (without declaration of daily quantum of smoked cigarettes) with that obtained from non smokers. The mean AgNOR value for the smoking group was $3.4 \pm 0.54 \mathrm{AgNORs}$ and $2.6 \pm 0.49$ for the non smoking group; the mean AgNOR value was significantly higher in cells of smokers than in non smokers $(p<0.01)$. In our study there was no significant difference between these groups. However no student has smoked more than ten cigarettes per day. This quantum seems not to be high enough to establish any influence on the proliferative activity of the cells from normal mucosa.

Our study showed that smears previously stained according to Papanicolaou and then to Feulgen can be restained using silver nitrate for AgNOR demonstration. In cytopreparations the mean AgNOR counts per nucleus appears to be a sensitive parameter, the specificity of which is high enough helping to distinguish benign from malignant lesions in all cases. The counting procedure (separate enumeration of satellites and clusters) consequently has no adverse effect on the measured cut-off value of 4.8 AgNORs per nucleus (data not shown).

The cut-off level of 70 percent of nuclei with more than three AgNORs per cell appeared to be a sensitive diagnostic method too. The time used for each evaluation could be drastically reduced from 45-90 minutes to 15 to 25 minutes per slide in comparison to the first described method. Values lying in the statistic threshold $\pm 15 \%$ should be countered accordingly to the full length procedure described first.

Applying these methods to twelve doubtful or suspicious cytological diagnoses, we were able to establish the histologically proven diagnosis of malignancy in ten cases and revealed benignity in two cases. Likewise the results were in agreement with the clinical follow up.

\section{Conclusion}

Cytologic investigation of smears from oral lesions macroscopically suspicious for cancer is an easily practicable, non-invasive, painless and accurate method, that may help to reduce the occurrence of invasive and thus fatal squamous cell carcinomas. The mean number of AgNORs per nucleus is a reliable marker for neoplastic squamous cells in oral smears. This method is able to increase the sensitivity for the detection of malignant and specificity for benign cells in oral smears and thus decrease the rate of cytologically false negative or positive diagnoses. In consideration of high labor costs this method can be used especially for clarification of cytologically doubtful cases. The latter method might be of diagnostic use.

We recommend the application of AgNOR counting as an adjuvant diagnostic method in oral smears in which the cytological differentiation between reactive and neoplastic epithelial changes is difficult.

\section{Acknowledgements}

We wish to thank Mrs. D. Bär for excellent technical assistance. Furthermore, we would like to express our thanks to Mrs. U. Tröger for the excellent preparation of slides.

\section{References}

[1] M. Bibbo, Comprehensive Cytopathology, WB Saunders Company, Philadelphia, 1991, pp. 541-614.

[2] A. Böcking and N. Freudenberg, Standardisierte Befunderstellung in der extragenitalen Zytologie, Pathologe 19 (1998), 235-236.

[3] M.R. Cardillo, Ag-NOR technique in fine needle aspiration cytology of salivary gland masses, Acta Cytol. 36(2) (1992), 14751.

[4] R. Carrillo, N. Sneige and A.K. el-Naggar, Interphase nucleolar organizer regions in the evaluation of serosal cavity effusions, Acta Cytol. 38(3) (1994), 367-72.

[5] M. Cox, N. Maitland and C. Scully, Human herpes simplex1 and papillomavirus type 16 homologous DNA sequences in normal, potentially malignant and malignant oral mucosa, Eur. J. Cancer B. 29(3) (1993), 215-219.

[6] J. Crocker, D.A. Boldy and M.J. Egan, How should we count AgNORS? Proposals for a standardized approach, J. Pathol. 158(3) (1989), 185-188

[7] J. Crocker and J. McGovern, Nucleolar organiser regions in normal, cirrhotic, and carcinomatous livers, J. Clin. Pathol. 41(10) (1988), 1044-1048

[8] J. Crocker and P. Nar, Nucleolar organizer regions in lymphomas, J. Pathol. 151(2) (1987), 111-118.

[9] J. Crocker and N. Skilbeck, Nucleolar organiser region associated proteins in cutaneous melanotic lesions: a quantitative study, J. Clin. Pathol. 40(8) (1987), 885-889.

[10] M. Derenzini, D. Hernandez-Verdun, A. Pession and F. Novello, Structural organization of chromatin in nucleolar organizer regions of nucleoli with a nucleolonema-like and compact ribonucleoprotein distribution, J. Ultrastruct. Res. 84(2) (1983), 161-172.

[11] M.J. Egan and J. Crocker, Nucleolar organizer regions in cutaneous tumours, J. Pathol. 154(3) (1988), 247-253. 
[12] S. Fakan and D. Hernandez-Verdun, The nucleolus and the nucleolar organizer regions, Biol. Cell. 56(3) (1986), 189-205.

[13] C. Goodpasture and S.E. Bloom, Visualization of nucleolar organizer regions im mammalian chromosomes using silver staining, Chromosoma 20 53(1) (1975), 37-50.

[14] H.P. Howald, M. Frenz and H. Pitz, Results from DÖSAK Observational Studies, In: Carcinoma of the Oral Cavity and Oropharynx, H.D. Pape, U. Ganzer and G. Schmitt, eds, Springer-Verlag, Berlin, Heidelberg, pp. 173-182.

[15] W.M. Howell, Selective staining of nucleolus organiser regions (NORs), in: The Cell Nucleus, H. Busch and L. Rothblum, ed., Vol. IX, Academic Press, New York, 1982, 89-142.

[16] M.S. Huang, M.S. Tsai, J.J. Hwang and T.H. Wang, Comparison of nucleolar organiser regions and DNA flow cytometry in the evaluation of pleural effusion, Thorax 49(11) (1994), 11521156.

[17] L.G. Koss, Diagnostic Cytology and Its Histopathologic Bases, 4th edn, Lippincott Company, Philadelphia, 1992, pp. 10821184.

[18] E.J. Mao, Prevalence of human papillomavirus 16 and nucleolar organizer region counts in oral exfoliated cells from normal and malignant epithelia, Oral Surg. Oral Med. Oral Pathol. Oral Radiol. Endod. 80(3) (1995), 320-329.

[19] V.V. Murty, A.B. Mitra, J.K. Sharma and U.K. Luthra, Nucleolar organizer regions in patients with precancerous and cancerous lesions of the uterine cervix, Cancer Genet. Cytogenet. 18(3) (1985), 275-279.

[20] G.R. Ogden, J.G. Cowpe and M. Green, Cytobrush and wooden spatula for oral exfoliative cytology. A comparison, Acta Cytol. 36 (1992), 706-710.

[21] C. Ostwald, P. Müller, M. Barten, K. Rutsatz, M. Sonnenburg, K. Milde-Langosch and T. Löning, Human papillomavirus DNA in oral squamous cell carcinomas and normal mucosa, J. Oral Pathol. Med. 23(5) (1994), 220-225.

[22] D. Ploton, M. Menager, P. Jeannesson, G. Himber, F. Pigeon and J.J. Adnet, Improvement in the staining and in the visualization of the argyrophilic proteins of the nucleolar organizer region at the optical level, Histochem. J. 18(1) (1986), 5-14.

[23] T.W. Remmerbach, H. Weidenbach, N. Pomjanski, K. Knops, S. Mathes, A. Hemprich and A. Böcking A, Cytologic and DNA-cytometric early diagnosis of oral cancer, Analyt. Cell. Pathol. 22(4) (2001), 211-221.
[24] J. Rüschoff, Nucleolus organizer regions (NORs), in: Diagnostic Tumorpathology, Gustav Fischer Verlag, Stuttgart, Jena, New York, 1992, pp. 1-144.

[25] J. Rüschoff, K. Plate, A. Bittinger and C. Thomas, Nucleolar organizer regions (NORs). Basic concepts and practical application in tumor pathology, Pathol. Res. Pract. 185(6) (1989), 878-885.

[26] H.D. Sampaio, A.M. Loyola, R.S. Gomez and R.A. Mesquita, AgNOR count in exfoliative cytology of normal buccal mucosa. Effect of smoking, Acta Cytol. 43(2) (1999), 117-120.

[27] D. Schön, J. Bertz and B. Hoffmeister, Bevölkerungsbezogene Krebsregister der Bundesrepublik Deutschland, Vol. 2, Robert Koch Institut Schriften, 1995, p. 374.

[28] L. Shechtman, R. Koren, A. Horowitz, I. Shechtman, M. Halpern and R. Gal, Diagnostic value of AgNOR staining in thyroid cytology, Anal. Quant. Cytol. Histol. 20(3) (1998), 187-191.

[29] K. Sujathan, S. Kannan, K.R. Pillai, B. Chandralekha, N.S. Amma and M.K. Nair, Significance of AgNOR count in differentiating malignant cells from reactive mesothelial cells in serous effusions, Acta Cytol. 40(4) (1996), 724-728.

[30] M.S. Trevisan, M.I. Souza and L.A. Magna, Nucleolar organiser regions of mesothelial and carcinomatous cells in effusions, Diagn. Cytopathol. 9(5) (1993), 492-497.

[31] K.A. Warnakulasuriya and N.W. Johnson, Nucleolar organiser region (NOR) distribution as a diagnostic marker in oral keratosis, dysplasia and squamous cell carcinoma, J. Oral Pathol. Med. 22(2) (1993), 77-81.

[32] J.C. Weir, W.D. Davenport and R.L. Skinner, A diagnostic and epidemiologic survey of 15,783 oral lesions, J. Am. Dent. Assoc. 115(3) (1987), 439-442.

[33] World Health Organization Collaborating Centre for Oral Precancerous Lesions. Definition of leukoplakia and related lesions: an aid to studies on oral precancer, Oral Surg. 46 (1978), 518-539.

[34] X. Xie, O.P. Clausen, J. Sudbo and M. Boysen, Diagnostic and prognostic value of nucleolar organizer regions in normal epithelium, dysplasia, and squamous cell carcinoma of the oral cavity, Cancer 79(11) (1997), 2200-2208.

[35] J. Zöller, M. Flentje, P. Sinn and I.A. Born, Evaluation of AgNOR and Ki-67 antigen as cell kinetic parameters in oral dysplasias and carcinomas, Analyt. Cell. Pathol. 7(1) (1994), 77-88. 


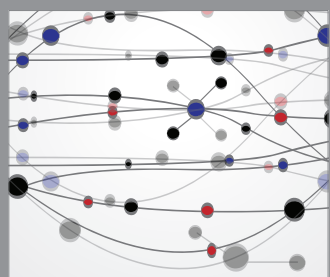

The Scientific World Journal
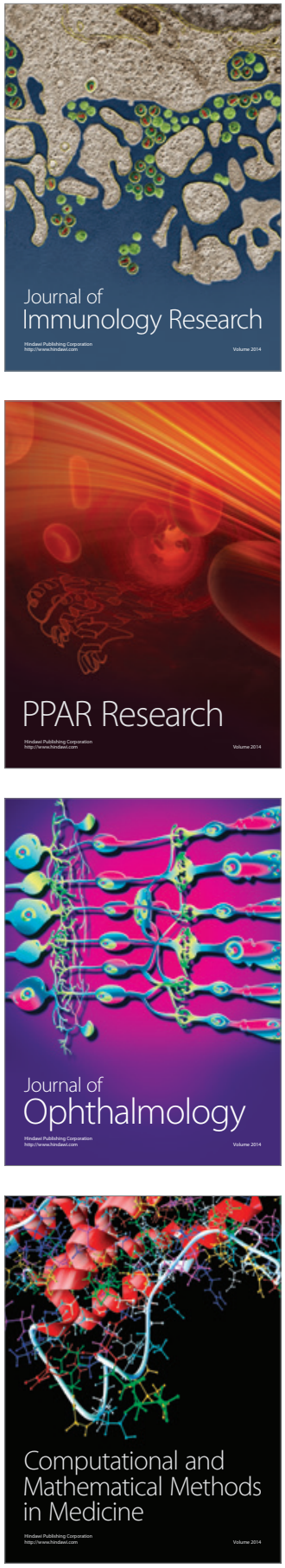

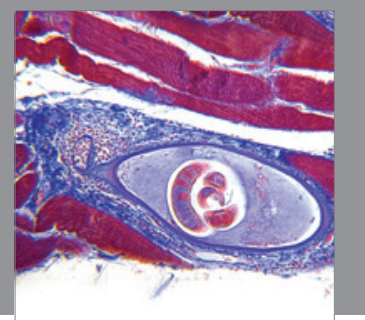

Gastroenterology

Research and Practice
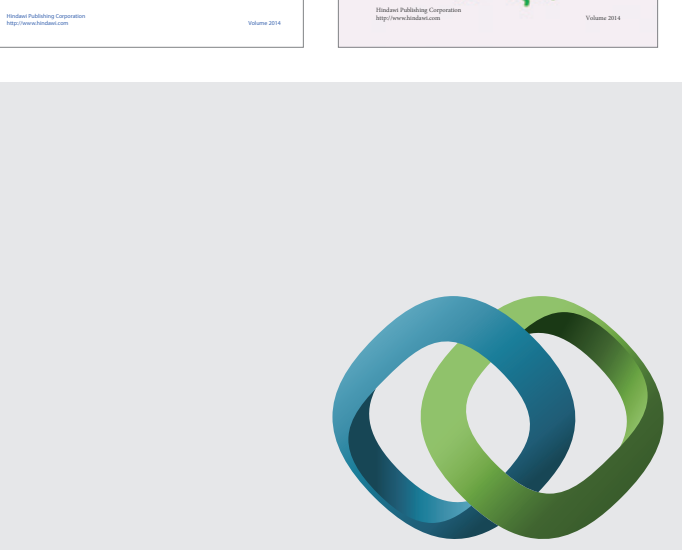

\section{Hindawi}

Submit your manuscripts at

http://www.hindawi.com
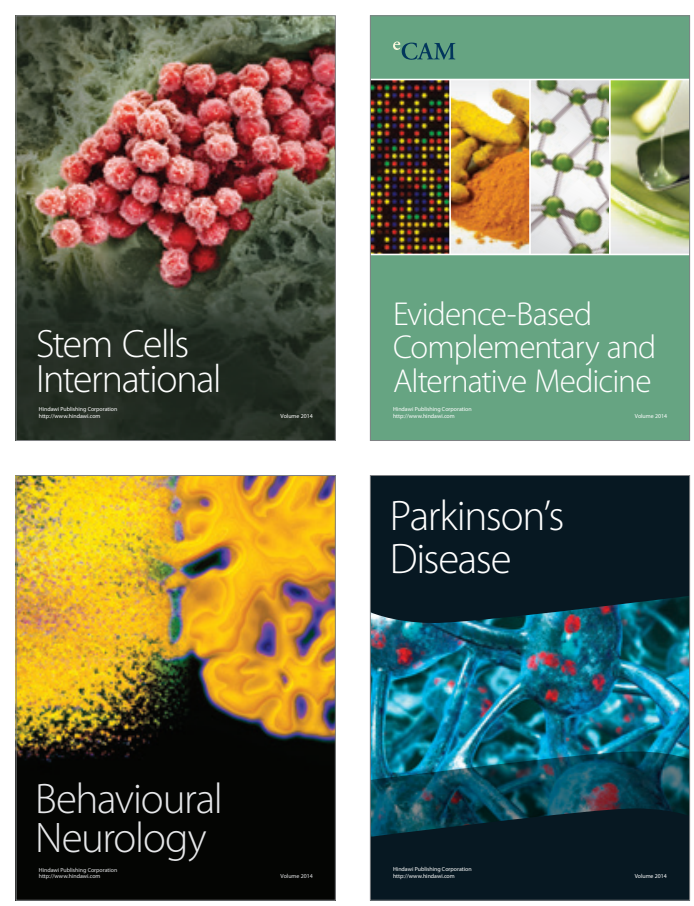

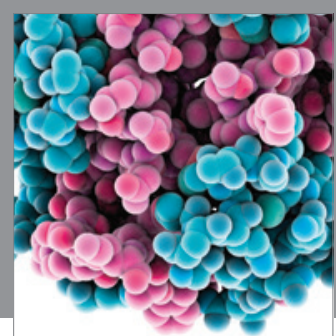

Journal of
Diabetes Research

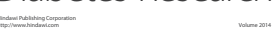

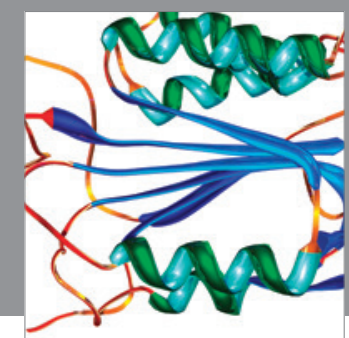

Disease Markers
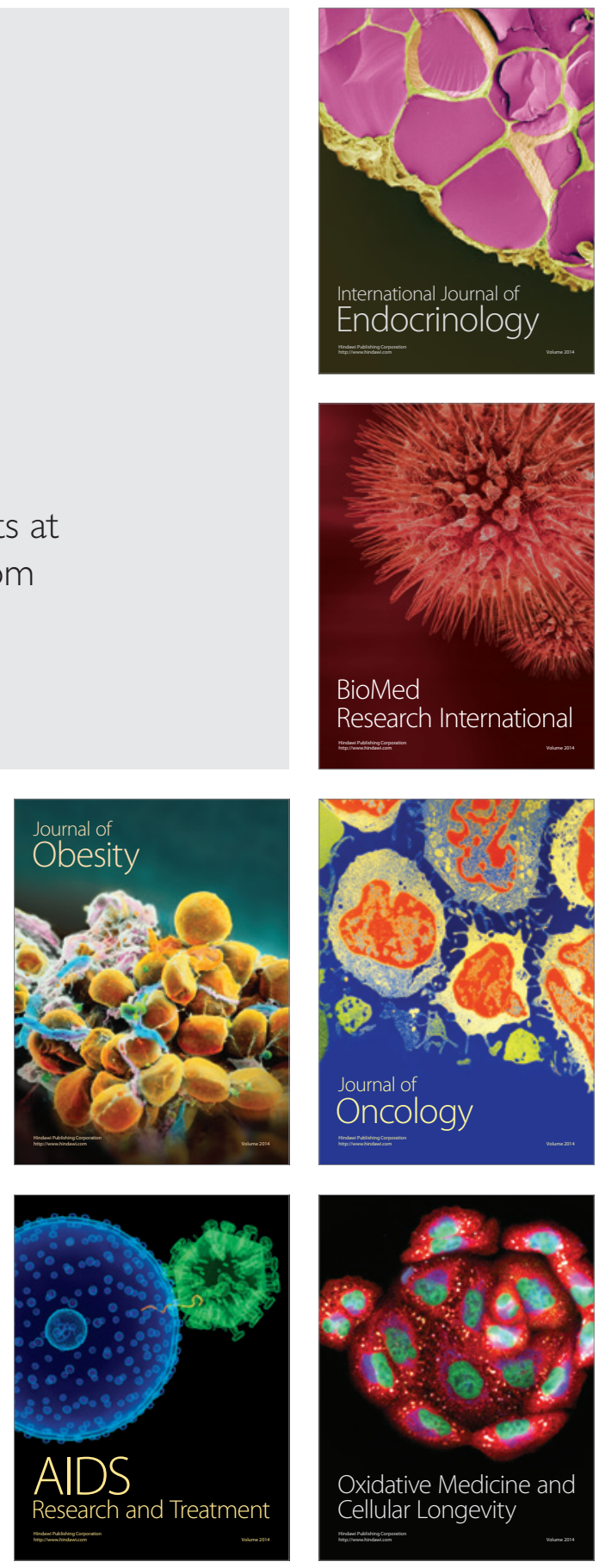